\title{
When 'Silence $=$ Death', Keep Talking: \\ Trust, Control and the Discursive Construction of Identity in the Canadian HIV/AIDS Treatment Domain
}

\author{
Steve Maguire \\ Faculty of Management \\ McGill University \\ 1001 Sherbrooke St. West \\ Montreal, Canada H3A 1 G5 \\ Tel: (514) 398-2115 \\ Fax: (514) 398-3876 \\ E-mail: smaguire@management.mcgill.ca
}

\author{
Nelson Phillips \\ Faculty of Management \\ McGill University \\ 1001 Sherbrooke St. West \\ Montreal, Canada H3A 1G5 \\ Tel: (514) 398-3602 \\ Fax: (514) 398-3876 \\ E-mail: phillips@management.mcgill.ca
}

Cynthia Hardy

Faculty of Economics \& Commerce

University of Melbourne

Parkville, Victoria, 3052

Australia

Tel: 61-3-9344-5344

Fax: 61-3-9349-4292

E-mail: c.hardy@ecomfac.unimelb.edu.au

9/15/2016

Revision for the Special Issue of Organization Studies:

Trust and Control in Organizational Relations

February 2000 


\section{When 'Silence $=$ Death', Keep Talking: \\ Trust, Control and the Discursive Construction of Identity in the Canadian HIV/AIDS Treatment Domain}

When we trust someone, it is because we believe there is something about his or her behaviour that makes it predictable. From a control perspective, it means that their behaviour is subject to some type of control mechanism. Building on this connection, we argue that trust and control are closely related and, in fact, that different forms of trust are associated with different types of control. We present a model explaining the control mechanisms associated with three different forms of trust commonly proposed in the literature. Based on a three-year study of the Canadian HIV/AIDS treatment domain, we then explore the dynamics of identification-based trust and normative control in more detail. Our findings reveal the discursive foundations of generating identification-based trust.

Descriptors: trust, control, identity, discourse, HIV/AIDS 


\section{INTRODUCTION}

In recent years, trust has become an increasingly popular topic in organization studies (e.g., Lane \& Bachmann 1998). However, although trust has been identified as an important topic (Gray 1989; Nathan \& Mitroff 1991), it remains an elusive concept for several reasons. First, different theoretical traditions offer different conceptions of trust (Lane \& Bachmann 1998) and yield conflicting prescriptions for its generation and maintenance. Consequently, we still know remarkably little about how trust is generated, particularly when parties are separated by conflicting goals and backgrounds (Hardy et al. 1998). Second, much of the work on trust glosses over crucial theoretical issues related to control (Knights et al. 1993). Authors argue that trust can be a functional equivalent of power and control (Lane \& Bachmann 1996; Das \& Teng 1998), and show how cooperation can be trust-based or power-based (Hardy et al. 1998). But, despite this work, the relationship between trust and control remains far from clear.

Drawing on the literature, we explore the links between different forms of trust and different types of control. We then examine the dynamics of trust and control among members of pharmaceutical companies and community organizations in the HIV/AIDS treatment domain in Canada. These groups are not naturally inclined to trust each other given a conflictual history that pitted community and industry against each other. Yet these groups did subsequently work together and, in order to do so, some form of trust between their representatives was generated. Our study thus provides an ideal case to explore the dynamics of trust and control in a complex institutional field characterized by conflict.

In exploring the links between trust and control we make a number of contributions. First, building on the existing literature and our case study, we develop a model explaining the underlying mechanisms of control that allow actors to 'trust' other actors with reference to three different forms of trust. Second, we discuss how actors can generate identification-based trust, a 
strong form of trust involving both predictability and goodwill. Third, we extend discussions of control to include the production of identity, demonstrating how the concept of a discursively constructed identity provides an important link between identification-based trust and normative control. We proceed as follows. First, we review the literature on trust and control and propose a theoretical framework linking them. Second, we discuss the case study and our method. Third, we present the results of our study. We show how normative control and identification-based trust can be generated through the discursive production of identity.

\section{TRUST AND CONTROL}

The literature on trust is large and growing rapidly (see Sitkin \& Roth 1993; Hosmer 1995; Mayer et al. 1995; Lane \& Bachmann 1998). But, while researchers agree that trust is important, there is virtually no consensus in the management literature on how to define it (Mayer et al. 1995; McAllister 1995). Some writers draw on personality theory and social psychology to describe trust in terms of individual expectations, beliefs and feelings. Others draw on sociology and economics and study it as an institutional phenomenon. In other words, in addition to trusting particular people (personal trust), actors can also trust organized systems (institutional trust) (e.g., Zucker 1986; Sydow 1998).

Despite the many different perspectives on trust, some commonalities exist: all of the different approaches include some idea of predictability. In other words, if we are confident that our predictions about the behaviour of others will come to pass, we will trust them. Where approaches vary, however, is in their emphasis on goodwill. Some approaches ignore it to focus solely on predictability (e.g., Luhmann 1979; Gambetta 1988), while others couple predictability with some form of goodwill - mutual reciprocity, the existence of common values, goals, understandings and/or the willingness to forego opportunistic behaviour (e.g., Lewis \& Weigert 1985; Ring \& Van de Ven 1992; Sabel 1993; Dodgson 1993; Zucker 1986). Some writers have 
argued that definitions of trust must include both predictability and goodwill to avoid conflating trust and power (e.g., Hardy et al. 1998).

Given our interest in the links between trust and control, the critical component of trust is the expectation of some predictable pattern in the behaviour of others (e.g., Luhmann 1979; Lewis \& Weigert 1985; Zucker 1986; Gambetta 1988). These predictable patterns suggest the existence of some underlying control mechanism that, once understood, could be harnessed by actors to facilitate the generation of trust. At the same time, various arguments have been put forth for including goodwill, at least in certain forms of trust. Our inclusive view of three different forms of trust - all of which involve predictability and one of which also involves goodwill - enables us to incorporate the various conceptualizations in the literature. We return to this issue after discussing the concept of control.

\section{Control and Its Forms}

The concept of control has a long history in the organization and management literature (Giglioni \& Bedeian 1974). In fact, for many, to command and control is to organize (Mintzberg 1979). Yet, despite general agreement about the importance of control, there is a surprising lack of consensus in this literature: writers diverge on what is meant by control and how it is best achieved (Das \& Teng 1998). Given that 'a large segment of the control literature explicitly recognized control as a regulatory process' (Green \& Welsh 1988: 289), we follow Leifer \& Mills (1996: 117) and define control as 'a regulatory process by which the elements of a system are made more predictable through the establishment of standards in the pursuit of some desired objective or state'.

Researchers distinguish a number of components of this process (e.g., Faulkner 1998; Das \& Teng 1998): control mechanisms such as contracts, budgets, incentives, and transfer prices; control outcomes which include the attainment of goals, predictability of behaviour, 
financial performance, and success; and the level of control which refers to 'the degree to which one believes that proper behaviour of the other party is ensured' (Das \& Teng 1998: 493). In other words, processes of control embody particular mechanisms that achieve a certain level of control over some object of control. For the purposes of linking 'trust' and 'control', we assume that the object of control is individual or organizational behaviour.

Based on the control literature, control can be coercive, remunerative or normative (e.g., Etzioni 1961). Conceptually, the first two types can be combined because they both involve externalized, overt mechanisms and can be explained in terms of resource dependency (Pfeffer \& Salancik 1978; Green \& Welsh 1988). Control of others is achieved by exchanging things that they need or want in return for behaviours aligned with goals (remunerative), combined with threats of interruption to these flows of important resources in the event of noncompliance (coercive). In other words, desirable behaviour on the part of others is obtained explicitly and overtly - this type of control is also known as 'formal' control (Das \& Teng 1998) - through rewards and punishments. For example, contracts are a clear example of a mechanism commonly employed to achieve this type of control in an organizational context.

Normative or 'social' controls (Das \& Teng 1998) are also common in organizational contexts, but these types of control are internalized and covert. Examples include norms, values and culture. With this type of control, desirable behaviour on the part of others is obtained without explicit rewards and/or punishments; actors' behaviour is compliant and predictable because they have internalized, and accepted as normal or appropriate, certain goals and standards. Behaviour is predictable and compliant as a result of auto-regulation. Researchers who have studied normative control from a critical perspective have pointed out the central role of actors' identities in this process. Actors 'become constituted in ways which render them more 
subject to those mechanisms and strategies of power which confirm this individualized sense of selves' (Coombs et al. 1992: 62). Identity - actors' sense of self, along with the meaning attached to the social categories in which they class and define themselves and others - is therefore an important vehicle for the normative control of behaviour.

To summarize, processes of control can be characterized by the degree to which they rely upon externalized coercive or remunerative mechanisms as opposed to internalized normative ones. This gives rise to two ideal types of control. Coercive/remunerative control is achieved through the negotiation of exchanges; actors' behaviour is compliant in exchange for expected rewards or the avoidance of punishments. Normative control, on the other hand, results from the negotiation of meaning; actors' behaviour is compliant because they believe it is the right and natural thing to do. Control in this latter case is at a deeper level, involving actors' preferences and not merely their expectations.

\section{Trust and Its Forms}

We build on the work of Shapiro et al. (1992) and Lewicki \& Benedict Bunker (1995) which proposes three distinct forms of trust. The models differ in that the former presents the different forms as independent, while the latter argues that they develop sequentially. For the purposes of this paper, what matters is only that three forms of trust can be observed, and not whether the three forms of trust co-exist, evolve from one to another, or are completely independent. $^{1}$

We also follow a number of writers (e.g., Zucker 1986; Ring \& Van de Ven 1992: Hardy et al. 1998) by examining these three forms of trust in terms of two commonly used definitions of trust found in the literature - trust as predictability and trust as predictability and goodwill. We argue that two of the three forms hinge on predictability while the third includes both predictability and goodwill. We then relate these forms to the different types of control discussed 
above. In adopting a critical stance toward control, we assume that predictability in the behaviour of individuals or organizations is the result of some sort of underlying control mechanism, which can be formal and overt, or unobtrusive and normative. The latter might operate below the surface and be difficult to observe, but it nonetheless exists and is a particularly important type of control from a critical perspective (e.g., Lukes 1974; Hardy 1985; Clegg 1989; Hardy \& Clegg 1999).

Calculus-based trust (CBT) stems from an ongoing calculation of the predictability of others' behaviour. Slightly broader and more encompassing than 'deterrence-based trust' (Shapiro et al. 1992) because it derives from considerations of rewards or incentives in addition to punishments. With this form of trust actors are assumed to be rational and to behave in their best interests. This means that other actors can calculate and predict their behaviour if they know all the costs and benefits associated with the various behavioural options. A trustor (the person wishing to trust another) can trust a trustee (the person being trusted) to behave in a certain way because it would be costly for the trustee to do otherwise. CBT is thus grounded in a system of exchanges of rewards and punishments. This 'transactional view of trust' hinges on predictability and there is no need for goodwill between actors.

I trust you because I can control what I want you to do and eliminate the risk of your unpredictability (Lewicki \& Benedict Bunker 1995: 153).

Actors seeking to trust others must control resources desired by them, while those seeking to be trusted must render themselves vulnerable to penalty or discipline. Thus, we suggest that coercive/remunerative control is the foundation of CBT since it is achieved through the negotiation of exchanges between trustor and trustee. The mechanisms of control used - rewards and punishments - are overt and formal. 
Knowledge-based trust (KBT) stems from an ongoing confirmation of the predictability of others' behaviour. Knowledge-based trust arises when a trustor observes a consistent pattern in the behaviour of the trustee and expects it to continue. It is grounded in knowledge - an accurate behavioural model - of the trustee. It, too, rests on predictability and does not imply goodwill. This predictability in trustees' behaviour, if it exists, is 'discovered' by trustors through observation of and experience with them. Trust arises because pre-existing, inherent consistencies in actors' behaviours create predictability that does not have to be induced with incentives or deterrents. The generation of this form of trust thus involves observing and comprehending others' behaviour patterns.

I trust you because I know enough about you to know what you will do, even if I cannot or will not try to control it (Lewicki \& Benedict Bunker 1995: 153).

Presumably, some process of control is acting on the trustee - something is giving rise to consistent patterned behaviour - but the locus of control is unknown and inaccessible to the trustor. Hence little room exists for the trustor to actively generate this form of trust. The trustee can present him/herself as trustworthy by behaving consistently, but there is not much that the trustor can do other than to read the signals correctly.

Identification-based trust (IBT) is grounded in an internalization of actors' desires and intentions. IBT has also been referred to as 'identity-based trust' (Coleman 1990), 'affective trust' (McAllister 1993) and 'relational trust' (Rousseau et al. 1998). When such trust is present, ‘the parties effectively understand, agree with and endorse each other's wants' (Lewicki \& Benedict Bunker 1995: 151). With this form of trust, the trustee recognize and accepts the validity of the trustor's needs, choices and preferences.

[The trustor] can be confident that his or her interests will be fully defended and protected, without surveillance or monitoring of the [trustee] (Lewicki \& Benedict Bunker 1995: 151). 
With this form of trust, goodwill is also present in addition to predictable behaviour; trustees forego opportunistic behaviour not because of deterrents, penalties or rewards but because it is seen to be the 'right' thing to do. Hence, IBT represents a strong form of trust, compared to the two other weak forms (Hardy et al. 1998).

The characteristics of this 'highest order of trust' (Shapiro et al. 1992: 371) lead Lewicki \& Benedict Bunker (1995) to argue that it is not connected with control. While we would agree that IBT is not connected with remunerative or coercive control, we argue that it is connected to normative control. As Lewicki \& Benedict Bunker (1995: 152) point out, one way to generate IBT is to 'form a common identity.' But, as critical theorists remind us, identities and their social meanings are not neutral. Rather, they are vehicles for the normative control of behaviour. An actor's sense of self — their own identity, which is always defined in relation to other identities — functions as an informal mechanism of control and, therefore, as a potential foundation for IBT. With IBT, trust and control connect around identity in the same way as they do around rewards and punishments in the case of CBT - IBT is generated in conjunction with normative social controls through the construction of particular identities.

To summarize, we have identified three forms of trust, all of which involve predictability: we trust others because we are confident in our predictions about their behaviour. Only IBT also assumes goodwill. IBT is thus important for a number of reasons. First, it is theoretically interesting because its generation depends on both predictability and goodwill. Second, many writers have assumed that IBT is contingent on pre-existing personal characteristics and/or common goals. They ignore the challenge of generating IBT in situations where these conditions do not apply, for example where groups are new to working together or have conflicting agendas, but wish to move beyond conflict. As a result, the generation of IBT has considerable 
practical relevance to many important situations where organizations and individuals are trying to work together. Third, despite this theoretical and practical importance, the generation of this form of trust is not well understood.

Given the basic understanding of the relationship between normative controls, the construction of identity, and the theoretical and practical importance of IBT, the remainder of this paper addresses the following research question: What are the dynamics of identificationbased trust and normative control and how can identification-based trust be generated? Our empirical study, described in the following section, was chosen to explore these theoretical and practical issues in a setting where they are transparently observable (Eisenhardt 1989).

\section{METHODOLOGY}

Our study focuses on the collaboration between pharmaceutical companies and HIV/AIDS community organizations that led to the creation of a new organization: the Canadian Treatment Advocates Council (CTAC) in the Canadian HIV/AIDS treatment domain. One of the authors has been actively connected with this domain since 1992 - as a founding member (19927) of the executive committee of a large fundraising organization devoted to HIV/AIDS - and was thus familiar with many of the main organizations and actors. Another author had been invited to participate in an early meeting of pharmaceutical companies and community organizations by a pharmaceutical employee.

We then set about interviewing key actors, including individuals who were actively and intimately involved in the birth of CTAC as well as those who had been excluded - or chosen to exclude themselves - from it. The interviews took place between 1996 and 1998. We gained access in two ways. First, using our contact in the pharmaceutical company, we identified key actors in both community organizations and pharmaceutical companies. Second, we extended the list of interviewees through the community contacts of the author familiar with the domain. We 
generated the list of interviewees using a 'snowball' sampling technique where we asked interviewees to identify other potential interviewees. We continued this process until no new names were generated. In total, we conducted twenty-nine, open-ended interviews with key actors in the Canadian HIV/AIDS treatment domain. The interviews were unstructured and questions changed as our understanding of the domain increased, as new events concerning CTAC took place, and in response to the involvement and position or role of the individual interviewee. In general terms, interviewees were asked to recount their story of the development of CTAC. Interviews were conducted in either French or English, depending on the preference of the interviewee. The interviews were taped and transcribed and, in the case of interviews in French, translated by one of the authors. The transcripts were analyzed using the NUD*IST qualitative data analysis software and were coded for references to 'identity', 'trust' and 'control'. Iterating between the data and the existing literature, we explored the relationships between these concepts. The quotations in this paper, taken from the interview transcripts, illustrate these relationships and concepts. We have disguised certain details that may compromise the anonymity of individuals in order to respect confidentiality.

\section{The Canadian HIV/AIDS Treatment Domain}

Since it was first identified in the early 1980s, over 6 million people have died of Acquired Immuno-Deficiency Syndrome (AIDS). More than 30 million people worldwide are living with HIV, the retrovirus believed to cause AIDS. The cumulative number of HIV infections has more than doubled since 1990, and it is estimated that 16,000 new infections occur each day. In 1997, another 5.8 million people became HIV-positive and 2.3 million died of AIDS. In Canada, approximately 40,000 people had tested positive for HIV as of the end of 
1997. Of the more than 20,000 cases categorized as full-blown AIDS, over 11,000 had already died from the disease. ${ }^{2}$

Medical research has focused on the treatment of individuals diagnosed with HIV/AIDS (referred to as People Living With AIDS, or PWAs), helping them to live longer and higher quality lives - at least in developed countries that can afford treatment. In this regard, HIV/AIDS represents a significant business opportunity for pharmaceutical companies. For example, worldwide sales of AZT, one of the early treatments for HIV/AIDS manufactured by Burroughs Wellcome (later merged with Glaxo), exceeded C $\$ 3.2$ billion by $1997^{3}$. In 1997 alone, Canadian sales of another HIV/AIDS drug produced by BioChem Pharma in partnership with Glaxo (currently Glaxo Wellcome) - 3TC - totaled C\$ 978 million and were expected to exceed C\$ 1 billion in $1998^{4}$. The arrival of another family of drugs - protease inhibitors - has ushered in a new era of treatment science in the form of combination or 'cocktail' therapy, where a number of substances, often from competing pharmaceutical companies, are taken simultaneously. Leading companies in this market include Abbot Laboratories (ritonavir), Hoffman LaRoche (saquinavir) and Merck Frosst (indinavir). Besides these treatments that target HIV directly, a wide variety of other medicines are used to treat the opportunistic infections associated with the disease. ${ }^{5}$

The primary aim of PWAs is to secure quick, safe and ethical access to effective treatments, while the pharmaceutical companies are concerned with commercial and profitmaking considerations. For example, issues like patent protection and pricing pit community objectives against corporate goals. Similarly, compassionate access programs (furnishing treatments that have not yet completed clinical trials and/or regulatory hurdles to some patients free of charge) often lead to conflict over the number of patients to be covered by a specific program, with the community demanding greater access to drugs than the companies are always 
willing or able to provide. The efficacy and safety of some treatments have also been challenged. Consequently, pharmaceutical companies have been the target of heavy criticism by activist groups like ACT-UP (AIDS Coalition To Unleash Power), which has not only accused companies of opportunistic profiteering, but has also called their products poison. Groups like WAKE-UP CANADA and AIDS Action Now! also engage in confrontation. Activist groups have regularly targeted pharmaceutical companies for protests at international conferences on HIV/AIDS, in attempts to discredit the industry generally and certain companies in particular.

More recently, however, members of the community and representatives from the pharmaceutical companies have been working together. In addition to providing funding for community organizations, pharmaceutical companies have consulted with the community. Consultation evolved into active collaboration as some companies established their own 'Community Advisory Boards' on which sat knowledgeable PWAs and other community members. These individuals shared information about treatment efficacy and safety (e.g. drug side effects), reviewed research protocols and compassionate access programs, and commented on the details of product launch events.

Consultation took a new direction in June 1995, when an employee of one of the pharmaceutical companies called a meeting with individuals from the main AIDS community organizations to review the relationship between the company and the community. A follow-up meeting in January 1996 discussed the idea of a permanent, national organization through which pharmaceutical companies and community members could exchange advice, opinions, and information about treatment issues. A taskforce of community members was established to develop recommendations regarding the constitution and mandate of this new organization. At this time, a number of other pharmaceutical companies expressed interest in such an 
arrangement. The general feeling was that a national organization was a valuable way to avoid duplication of efforts, to prevent community individuals being overworked, and to ensure that the involvement of these individuals in consultations with pharmaceutical companies was legitimate in the eyes of the community. The taskforce circulated its draft proposals in April 1996 at a meeting between the pharmaceutical company and community members, which was followed by meetings between two other pharmaceutical companies and community members.

In June 1996, the structure of the national organization was decided and its name was chosen - the Canadian Treatment Advocates Council (CTAC). A number of pharmaceutical companies attended these meetings and agreed to fund CTAC. It was to be autonomous controlled neither by a single community organization, nor by the pharmaceutical companies. Its objectives included the articulation of a united voice regarding policy and treatment advocacy at the national level; the development of skills regarding treatment advocacy at the regional and provincial level; and the provision of a central access point for pharmaceutical companies to obtain advice on treatment and policy issues of importance to the community. In September 1996, the interim CTAC board held meetings with four pharmaceutical companies. CTAC was eventually launched in 1997, bringing together representatives of more than 15 regional and national HIV/AIDS organizations and representatives of several major pharmaceutical companies, including Glaxo Wellcome, BioChem Pharma, Abbott Laboratories and Merck Frosst. Subsequently, community representatives were organized into smaller liaison teams to each maintain an ongoing relationship with a particular pharmaceutical company.

\section{TRUST AND CONTROL IN THE CANADIAN HIV/AIDS TREATMENT DOMAIN}

For CTAC to be created and to function, coordination between two highly disparate groups had to be achieved. So, as one might expect when previously separate and very different actors are brought together to collaborate, issues of trust and control quickly came to the fore. 
Both community and pharmaceutical participants in CTAC recognized mutual trust as critical and desirable. They also generally agreed that trust had been generated:

We're just going to have to, as individuals, make efforts to link. That's all I'm really trying to do. ... I'm just going to see my role as making sure the linkages and the coordination happens and I'll do that as subtly as I can ... nothing happens without trust. (community member, discussing the relationship between community and industry participants in CTAC)

What they had which was also very, very valuable was the informal relationships. ... They had established that relationship and they had established a level of trust with patients and with the community. (pharmaceutical company employee, discussing the relationship between another pharmaceutical company and the community)

Despite the differences between pharmaceutical company employees and community members, trust was generated as the HIV/AIDS treatment domain evolved from a more traditional disease treatment domain to its current state. Over and over again in our analysis, we came across actors' accounts of events in which they evoked reasons for their trusting and collaborative relationships - as well as other mistrusting and conflictual interactions - that rested upon who they were in relation to who others were. It became clear that the 'reciprocal orientations and shared interpretive assumptions’ (Lewis \& Weigart 1985: 456) employed by actors implied normative controls which, in turn, served as a basis for trust. Consequently, we argue that IBT emerged in the Canadian HIV/AIDS treatment domain and that discursive activity that generated new identities was key to generating and maintaining this trust.

In examining the construction of new identities as the discourse of the HIV/AIDS treatment domain in Canada evolved, it is clear that neither the identities associated with traditional disease treatment domains, nor the identities associated with early interactions between the HIV/AIDS community and the pharmaceutical industry, lent themselves to the generation of trust. However, over time, other identities were constructed that did form a basis for subsequent trust and collaboration. These identities were anchored in a reciprocal 
understanding that presumed certain norms would control or guide behaviour. Two broad discursive approaches were employed by actors. The first approach involved reconstructing myths of the Canadian HIV/AIDS treatment domain and, in so doing, discursively constructing new identities that became embedded in domain-level discourse. The second approach involved actors discursively constructing themselves and others by assigning individuals to particular identities in the domain-level discourse. The enactment of these identities is governed by mechanisms of normative control — the norms, values, and preferences associated with each identity — and thus allowed trust to be generated.

\section{Reconstructing Myths: the Creation of New Categories of Identity}

In this section, we show how the 'myth' associated with the 'typical' disease treatment domain was reconstructed in different ways, which allowed new categories of identity to emerge.

\section{Original Myth: 'patients' to be protected from 'pharmaceutical companies'}

The HIV/AIDS treatment domain, characterized by extensive formal collaborative interactions between the community and the pharmaceutical industry, is atypical. In the 'traditional' disease treatment domain, a skilled, professional elite - pharmaceutical companies, medical researchers and their institutions - produces scientific knowledge and treatment products, often using a passive group of research subjects in their work. Other powerful actors then approve these products - the government formally approves sales through health regulation, while insurers effectively approve treatments by agreeing to pay for them. Another elite body physicians - then dispenses these products, via another elite group - pharmacists - to a group of passive disease patients or victims. Pharmaceutical companies and patients do not interact, much less collaborate, since they are clearly - and deliberately - separated by physicians, pharmacists and governments who act as gatekeepers. 
The construction of individuals as 'doctors' and 'patients' means that the latter will in all probability trust the former. The identity of 'pharmaceutical company' is constructed less positively with respect to 'patients', making trusting relations problematic. While 'patients' are constructed as naive, medically illiterate, desperate victims vulnerable to 'marketing', 'pharmaceutical companies' are constructed as opportunistic, profit-seeking private entities who are skilled 'marketers'. These constructions justify the roles of both the medical profession and government (indeed, the 'Health Protection Branch’ of Health Canada) as gatekeepers between pharmaceutical companies and patients. The traditional disease treatment domain keeps these two actors apart: governments mediate the introduction of new products with their drug approval powers; doctors mediate the sales of approved products with their prescribing power; and pharmaceutical companies cannot market their products directly to patients. Thus, patients can trust governments and the medical profession, but not pharmaceutical companies.

\section{Reconstructing the Myth (I): From 'patients' to 'People Living with HIV/AIDS'}

From its beginning, AIDS was not a typical disease. First, it was new and not well understood by the existing medical elite. Second, it was wrapped up in the emotional issues of death and sexuality. Third, it killed in a rather horrific way. Fourth, it attracted lots of media attention. Finally, and particularly important to the eventual restructuring of the domain, its epidemiology resulted in an early concentration of cases in a specific marginalized - yet organized and politicized - social group: the gay community. Battle-wise from their struggles over gay rights, and also informed by lesbian-feminist critiques of medical paternalism, this new disease 'clientele’ posed a serious challenge to existing structures, organizations and institutions associated with medical and social services delivery, as well as medical knowledge production (Wachter 1991; Roy 1995). 
AIDS presented a serious challenge to established identities - and patterns of trust and control - in the treatment domain. A knowledge and treatment vacuum emerged as a result of a very public display of scientific uncertainty and institutional impotence in the face of this new crisis. Suddenly, old understandings about who was knowledgeable, who could and could not be trusted, and who should and should not be granted control, were open to contestation. For example, early on in the epidemic, the expertise of the 'doctor' was in doubt. Not only did physicians not have the expertise to deal with this new challenge, some were patently unwilling to acquire it or even to act in the interests of their patients. Many early AIDS patients were abandoned as discrimination, bigotry and fear led to some doctors 'dumping' their patients.

PWAs began to reject the identity of 'patient' and the victimhood it implied. 'Patients' (from the French 'patienter', which means to wait, as in a physicians' waiting room, and originally from the Latin, where it means 'to suffer') would be 'patient' and suffer in silence no longer. 'Silence $=$ Death', an expression made popular by the activist group ACT-UP, became the call to action for HIV/AIDS patients seeking to redefine themselves and their role within the domain. Community members stressed that they were neither 'patients' nor 'victims,' but 'people living with AIDS.'

It was agreed to use the term 'patient' very carefully, using either PWA or People Living With AIDS wherever possible’ (pharmaceutical company employee).

This term [People Living with AIDS] is preferred because, quite simply, 'We are people. And we are living with AIDS.’ (community member).

The identity of PWAs, collectively, is thus very different than that of traditional patient groups. The notion of patients as passive, ignorant, requiring the medical expertise of an elite was successfully deconstructed and replaced with a notion of a patient group as empowered, informed and organized decision-makers. Empowered PWAs, less trusting of the traditional 
authority of the medical elite, as well as the government with its slow bureaucratic approval of treatments, began to demand and exercise more control over the treatment 'pipeline'.

These HIV/AIDS community members 'opened up the black box' of medical and pharmaceutical science (Epstein 1996). Consequently, the HIV/AIDS treatment domain has become notable for the visible and active presence of patients, lay-people and community organizations in the production, dissemination and application of medical scientific knowledge. This, in turn, brought them into direct contact with the pharmaceutical companies researching, producing and marketing the drugs on which their lives depended. No longer separated by gatekeepers, patients and pharmaceutical companies began to interact.

\section{Reconstructing the Myth (II): 'Activists' in conflict with 'Pill-pushing Profiteers'}

The initial relationship between the community and industry was not one of trust and collaboration. Along with the emergence of the identity of PWA, another new identity emerged in the HIV/AIDS discourse - 'AIDS activist'. The talk and activities of groups like ACT-UP did much to establish the meaning of this identity. 'Activism' was premised on overt struggle and conflict, as the following statement indicates.

AIDS Action Now! is a Toronto-based activist group fighting for improved treatment, care and support for people living with AIDS and HIV infection. We work to transform HIV infection into a chronic manageable illness by making the research, health care and social service systems deliver optimal treatment. (1995 mission statement of activist group AIDS Action Now! emphasis added)

HIV/AIDS activists were associated with media-savvy protests like chaining themselves

to buildings and hurling fake blood at pharmaceutical company representatives. 'Activists' did not trust pharmaceutical companies, who were viewed and denounced as 'profiteers' to a chorus of 'Shame! Shame! Shame!' in a series of protests, rallies, pickets, disruptions of news conferences and other dramatic behaviour. Some companies were subjected to particularly vehement criticism. 
They [a particular pharmaceutical company] are disgusting North American pill pushers who have the American mentality and who try to push pills all the way down your throat until you vomit. Well, the community vomited on them, and in my opinion, they should have vomited harder. (community member)

Not surprisingly, pharmaceutical companies also interpreted this relationship as conflictual.

You may remember those years, the activism level was very, very high. There was real antagonism between private companies and the community. (pharmaceutical company employee)

Over time, however, a more nuanced sub-identity of 'treatment activist' emerged. This identity, while it did not preclude traditional forms of HIV/AIDS activism, also signified an accompanying high level of medical and scientific professionalism. Here were the original HIV/AIDS 'activist-experts’ (Epstein 1996). Initially an identity dominated by white, uppermiddle class, professional gay men, 'treatment activists' were different from 'activists' by virtue of their professionalism and the ease with which they moved within scientific and policy-making circles.

Though empowering, neither the identities of 'activist' nor 'treatment activist' was likely to produce trust between the HIV/AIDS community and the pharmaceutical companies. The former was firmly premised on conflict, while the latter was ambiguous in terms of the norms for interacting with industry.

\section{Reconstructing the Myth (III): 'Advocates' collaborating with 'Compassionate \& Consultative Partners'}

Eventually, another identity, 'treatment advocate', emerged as 'treatment activism' was split conceptually and discursively by both community members and industry people into 'activism' and 'advocacy'.

Advocacy is more the kind of lobbying, the preparations of briefs, all that kind of stuff ... whereas activism I think is more the on the street, in your face, confrontational kind of activity. (community member) 
We kind of knew that there were people who would help people [advocates] and then we kind of knew there were political activists and the two aren't necessarily the same. (pharmaceutical company employee)

Gradually, the ambiguity between activist and advocate was resolved in a way that facilitated trust between community and industry: advocates were constructed as professionals, with the norms that this term implies, and as being far more amenable to collaboration than activists. They were, therefore, seen as far more trustworthy and acceptable as partners by the pharmaceutical industry.

I'm not and we're not in the activism business. We're a pharmaceutical company. ... When time comes for funding a pure activism activity I'm not there. I say, this is not why we're there. .... I wouldn't want to fund a really up-front activism. So I think it's acceptance on both sides of limitation. (pharmaceutical company employee)

There was a debate about activist versus advocate because we felt that activist has the ACT-UP connotations of, you know, burning things, and chanting and falling down so the drug companies were scared of that so we just changed it to advocate. The reality is advocacy is what we do. (community member)

In contrast with activists, treatment advocates were constructed as reasonable, knowledgeable, business-minded professionals with whom industry could discuss matters rationally, negotiate and even collaborate. The normative controls evoked by this identity implied actions involving partnership, dialogue and compromise rather than dissent, disagreement and conflict.

The identity of advocate also has significant implications for the relationship between advocates and the wider community that they claimed to represent. Whereas the identity of 'activist' tends to imply individualistic action, that of advocate implies representation of a constituency. Advocates, unlike activists, are not totally free to act according to their individual preferences.

It really is difficult because you also have to be patient with people who are learning how to be advocates. One of the fundamental tenets of being a good advocate - which most advocates don't follow by the way - is that you don't speak for yourself. You solicit the opinion, you inform your constituency about 
what their options are, you give them your opinion as to what you think they should do, but they can decide different. Anything else is abuse. It's imposing... Advocacy is not about me deciding what I think is best. (community member)

Given these normative controls, the community could trust advocates to represent their case collectively, rather than acting as individuals. CTAC - as the Canadian Treatment Advocates Council - served to reinforce this identity and these controls.

Trust between community and industry did not rest solely on the new identity of advocate: it also required the emergence of an alternative identity to 'profiteering' pharmaceutical company. As the attention of pharmaceutical companies was drawn to the changes in the domain, they began to redefine themselves. They became 'partners':

Although [our] primary mission is to develop and manufacture pharmaceuticals, the company sees it has a much broader role to play - one which involves working with all players in health care to find solutions that will enable them to prevent and treat health problems. (pharmaceutical company promotional brochure)

Pharmaceutical company employees maintained that this new identity and the new 'educational' relationships - not 'marketing' as they frequently stress - have fundamentally changed their work and will, in fact, spill over to other fields.

I really feel that, in the long run in the pharmaceutical companies, we are going away from the traditional conventional marketing. The marketing will take different twists. It is going to move towards education and information .... (pharmaceutical company employee)

Community members confirmed the durability and potential scope of these changed identities and relationships.

There are many more things that ultimately will be of benefit from this model. ... The model may be that it's not just AIDS drugs, it's what should the relationship be between consumers and the companies that provide the drugs and the products that are health-related, because I think we'll continue to go on our mad-dance with help through drugs for a long time - I'm not about to change but some of those relationships will probably change ... because I think we're doing something that goes beyond in scope just AIDS. ... But I believe that we could be redefining 
some of the way Canadians, as consumers, deal with governments and with the products that they put into their bodies. (community member)

In summary, at the level of the domain, myths were reconstructed in such a way that new categories of identities emerged, in particular 'treatment advocate' and 'compassionate and consultative partner'. The normative controls associated with these identities produced behaviour conducive to trusting relationships. Trust thus emerged not from the creation of one collective identity but from the emergence of different, complementary identities.

\section{Reconstructing Actors: the 'Assignment' of Individuals}

Besides reconstructing entire categories of identity, actors also reconstructed individuals - themselves and others - by drawing upon and harnessing the changing discourse in the domain. Besides categorizing themselves as 'advocates' and 'compassionate and consultative partners', individuals involved in creating CTAC also constructed themselves as being 'the same as' those with whom they were collaborating, wherever possible, along important dimensions of identity. Hence advocates constructed themselves as business-minded community people while company representatives constructed themselves as community-minded business people. While this sharing of identity helped to generate IBT, it was no easy task. A careful balance had to be struck because, as actors constructed themselves as being similar to their collaborating partners, they risked losing the identity that they shared with the constituencies that they represented.

\section{Constructing Actors as 'Advocates' collaborating with 'Compassionate and Consultative Partners'}

In their conversations with pharmaceutical employees, community members constructed themselves discursively as 'experts' or 'professionals' with appropriate medical and policy knowledge and who also understood the world of business. That individuals who had been perceived to be 'activists' - with all that that implies - could successfully harness these identities and construct themselves as knowledgeable and business-minded, resembling their 
pharmaceutical company counterparts, at first surprised this latter group. Nonetheless, it facilitated the generation of a trusting relationship:

I can remember meeting my first two head honcho activists.... I didn’t know want to expect and I was told that the one guy that I was to meet was actually an unbelievable activist and probably would give me a rough time. I found the guy to be an absolutely unbelievable gentleman - very bright, gold medal winner ... and with an MBA. The other guy was a business major and we all sat down and talked about things and they asked me some pretty pointed business questions and then I gave them reasonable answers and I think that was that. (pharmaceutical company employee)

Likewise, pharmaceutical company employees presented themselves as similar to community members. They shared the goals of those with whom they sought to launch the collaboration and, at times, were similarly frustrated by the machinations of big business:

I've been out to their meetings and participated in whinings ... I think maybe at times, I can go a little too far over the line but that's me. That's where I want to be anyway, you know... if I wasn't here, I'd be on the non-profit side. (pharmaceutical company employee)

In addition, they were 'open', 'open-minded', and 'liberal' - all code words for not being homophobic. This construction of self was critical - neither community members nor pharmaceutical companies could 'trust' individuals perceived in any way to be homophobic.

We were looking for people who were really quite open and transparent for the community. Very HIV oriented. In other words, it wouldn't bother them at all to be working in this kind of community and at the same time they would be open enough to be able to work solidly with them. Those are values ... that would be valued by the community. (pharmaceutical company employee)

Community members involved in the collaboration began to recognize pharmaceutical company employees as more like them - as potential partners - and clearly differentiated them from the stereotypical profiteering 'company men':

He's [pharmaceutical company employee] trying to take a role in community development. He has a real commitment. He's out there. He's trying to be a real presence. ... [An employee of another pharmaceutical company] is in there too but I've met him and I get a sense of how he scrutinizes some of these requests and he's really tough in terms of evaluating why they would give money to a 
particular initiative ... it has to have certain rates of return before they will consider it.' (community member)

Yet, by their own admission, these identifications with their collaborative partners simultaneously created disidentifications with the constituencies they represented. Just as trust is granted to those with whom one identifies, it may be withheld from those whom one suspects of being different. As they harnessed those dimensions of their identities that they shared with pharmaceutical company employees, the treatment advocates became aware of their 'other-ness' vis-à-vis the vast majority of PWAs.

What worried us here at [a particular community organization] and what still worries us is elitism. Especially in treatment issues, the people who find themselves around the table discussing were an elite, and some took themselves to be more important than they really were. It's not because you understand treatment issues that makes you God. Unfortunately, some people at the table thought too much of themselves. ... It's become an unbelievable elite treatment group into which we cannot integrate ordinary people and the ordinary everyday life issues of how many hundreds of poor people that we see each year. We must also address the question of poverty, which is connected to treatment issues. It's those sorts of things that will be missing [with certain advocates] ... It's not because you read 50 scientific journals per year that you are living in the real world. (community member)

Similarly, pharmaceutical company employees working with the community became increasingly aware of their difference from other employees.

We are testing all sorts of things that people [in this company] have never done before so we are working very freely compared to a lot of areas in the company here. ... The way we deal with our physicians is also different so we are doing things that are a little bit different from the rest of the companies and because we are so different also in nature, it is easy to justify (pharmaceutical company employee).

In summary, a second approach observed in the case study involved actors assigning themselves to the new domain-level identities. Discursive activity in this case also involved actors constructing themselves, wherever possible, as being 'the same as' those with whom they wished to generate trusting relationships. 


\section{DISCUSSION AND THEORY BUILDING}

In this section, we review our findings in the context of the trust and control literatures presented earlier. As we enfold findings with the literature (Eisenhardt 1989), we first present a broad model that explains the link between all three forms of trust and different types of control. We then relate our findings to the post-structuralist literature on identity in order to better understand IBT and how it can be generated through discursive activity. Finally, we highlight how IBT is associated not only with predictability but also with goodwill and the willingness to forego opportunistic behaviour that is commonly associated with trusting relationships.

\section{Trust and Control}

Table 1 describes CBT as ongoing confidence in the predictability of the trustee, grounded in the calculation of rewards and punishments. It is based on coercive/remunerative control and generated through the negotiation of exchanges between trustor and trustee. The mechanisms of control that are used - rewards and punishments - are overt and formal. Actors seeking to generate this form of trust must have access to resources valued by potential trustees, which can be exchanged for compliant behaviour. The exact form of these resources will vary widely according to the situation, but generally they include such things as money, perks, favours, etc. In other words, trust is generated by the trustor's active manipulation of the predictability of the trustee's behaviour through the overt structuring of rewards and punishments. This transactional form of trust has been subjected to considerable study by researchers from a variety of disciplines who adopt an exchange view of social life, including economists, political scientists, as well as resource dependency theorists. As a result, our understanding of the dynamics of generating CBT is relatively clear. Probably the biggest debate regarding this form of trust is whether it really constitutes trust at all, because of the power 
differential that is involved as one party controls the other (e.g., Fox 1974; Grannovetter 1985; Hardy et al. 1998).

— Table 1 near here -

KBT is described as ongoing confidence in the predictability of the trustee, grounded in the trustor's knowledge of the trustee. With this form of trust, the locus of control is unknown and inaccessible to the trustor, hence little room exists for the trustor to actively generate this form of trust other than through observation of and learning about the trustee - reading the signals of the trustee accurately. Resources that help in this regard are informational and include data on the potential trustee's behaviour, the trustor's cognitive and computing skills, etc. Cognitive psychology and theories of learning offer insight into processes of reading signals and building models accurately, but generally it is difficult for the trustor to actively generate this form of trust; he or she is confined to a relatively passive role of registering the predictability of the trustee. In fact, much of the organizational literature argues that this form of trust cannot be generated but only emerges 'naturally' or 'spontaneously' through increasing interaction and familiarity (e.g., Dasgupta 1988; see Sydow 1998).

IBT is described as ongoing confidence in the predictability and goodwill of the trustee, grounded in trustee-trustor identification. We show that while IBT is not associated with the formal, overt control associated with CBT, it is nevertheless underpinned by a type of control — normative - which is covert and unobtrusive. IBT is generated by shaping and moulding identities in ways that increase identification between trustor and trustee. This form of trust has received considerable research attention from disciplines like social psychology. However, we argue that, to fully understand the processes of identity construction, one must refer to poststructuralist sociological theories of identity. These approaches suggest that the key resources to 
generating IBT are discursive - the trustor's access to and voice in key conversations, etc. which allow the active manipulation of the predictability and goodwill of the trustee through the construction of identity.

\section{Generating Identification-Based Trust}

Prescriptions for generating IBT have, in the past, stressed the importance of a common shared collective identity (Shapiro et al. 1992; Lewicki \& Benedict Bunker 1995). Yet our analysis of the case study suggests that trust can also be generated between actors who do not share an identity, if their different identities are complementary and mutually understood to imply normative controls on behaviour that evoke predictability and goodwill. In other words, IBT is possible when actors mutually understand and accept that acting in each other's interests and foregoing opportunism are normal, right and preferred behaviours. Identity is thus the key mechanism: actors are subject to the normative controls on behaviour associated with the identity that they possess or - stated differently to reflect a less essentialist perspective on this construct the identity that they have been constructed as possessing. If actors can credibly construct themselves and others as possessing particular identities - and hence as subject to particular normative controls - then trust is possible. This trust leads actors to exhibit goodwill and to tolerate situations of exposure to risk, harm and opportunism.

It is important to contrast our notion of identity and its 'construction' with traditional, 'essentialist' approaches to identity. The latter tend to portray race, gender, age, etc. as 'innate characteristics that define the essence of the individual' and 'reflect essential differences in attitude, personality and behaviour' (Litvin 1997: 201, 204). Our approach to identity, on the other hand, focuses on the socially constructed meaning attached to categories of identity. Meaning emerges from the productive power of discourse and is continuously created and re- 
created through conversation and narrative. According to post-structuralist views, identity is discursive; there is no 'true' self or even selves.

[T]here are no identities that exist in stable, self-contained form across time. Poststructuralists reject the positivist premise that the identities of phenomena lie in being and they reject the phenomenological assertion that identities are constituted in essences that have trans-historical potential. (Holmer-Nadesan 1996: 50).

Instead, 'it is useful to treat identity as a narrative, or more properly speaking, a continuous process of narration where both the narrator and audience formulate, edit, applaud and refuse various elements of the constantly-produced narrative' (Czarniawska-Joerges 1996: 160; also Alvesson 1994). Identity is co-constructed with others, but there is never one, single 'autobiography'. Rather, identity is produced from many biographical and autobiographical acts that contradict, dominate and subvert each other (Czarniawska-Joerges 1996). An actor's identity is precarious, emerging from and embodied in discursive struggle (e.g., Rodriques 1996; Phillips \& Hardy 1997; Hardy \& Phillips 1999). This approach to identity emphasizes its fragmented, ambiguous, multiple and - importantly for those seeking more trusting, collaborative relations changeable nature.

IBT thus arises from an inter-subjective social 'reality' based on shared meanings between trusting partners. As a number of writers have pointed out, social action rests on interpretive, communicative sense-making (Berger \& Luckmann 1967) as meaning is constructed through specific communicative events or conversations (Collins 1981). Trust arises as these conversations invoke a shared reality or 'myth' (Hardy et al. 1998). Within these myths, certain identities can trust certain other identities to behave predictably with goodwill because, within the myth, it is appropriate behaviour. To accept and possess a particular identity means to be subject to a particular set of normative controls on behaviour. The generation and 
maintenance of IBT is therefore intimately tied up with the construction of myths and the identities that populate them, as we have demonstrated in our case study.

\section{Identification-Based Trust and Goodwill}

We have stressed that, unlike CBT and KBT, IBT involves goodwill. Our case study contains a number of examples of instances where actors, because of IBT, exposed themselves to risks and put themselves in situations where the behaviour of other actors could have been harmful or opportunistic. The existence of CTAC is itself evidence of behaviour that would be unthinkable without IBT. For example, pharmaceutical companies, which are adamant that they are 'not in the activism business' and 'wouldn't want to fund really up-front activism,' are nevertheless comfortable with publicly supporting 'advocacy'. In addition, pharmaceutical companies regularly trust their community partners in CTAC with proprietary information, despite the opportunities to pass these secrets on to rival companies or to more radical activist organizations. Indeed, that such sensitive and valuable information - about new products in R\&D pipelines, early results of biochemical testing, research protocols, efficacy and safety data from clinical trials, etc. - is shared with non-scientists outside these firms is quite remarkable. Trust evolved to such a degree that companies involved members of community organizations in internal decision-making about how to allocate their HIV/AIDS philanthropic budgets.

Similarly, the existence of CTAC is evidence that community organizations and their members were also willing to expose themselves to risk as a result of IBT. This is because the legitimacy that community members can add to pharmaceutical company products and activities - by what they say on certain issues, by their silence on other issues, by their presence at product launches and company events, etc. - creates a risk of exploitation. By participating in CTAC, community organizations and their members were open to charges of being coopted, yet they persisted. The ongoing collaboration between industry and community would have been 
impossible if CTAC members were not convinced that attitudes, values and behavioural norms of pharmaceutical companies had evolved to such an extent that they were now dealing with 'consultative and compassionate partners,' who could be trusted, rather than 'pill-pushing profiteers' who could not.

As mentioned earlier, some writers have stressed that to reap all the benefits typically associated with trust, it cannot be based on predictability alone but must also embody goodwill. Much of the literature assumes the pre-existence of goodwill in some form or another, and hence avoids the difficulties of creating it, especially when disparate groups are involved (see Hardy et al. 1998). Our case study shows that the discursive production of identity helped former adversaries to transform their relationships and enact goodwill in ways that led to aligned - if not common - goals, values and understandings, as well as the willingness to forego opportunistic behaviour. Further, they did so without having to form a common shared identity; instead they constructed themselves in ways that simultaneously differentiated them from, and connected them to, their partners. The construction of these complementary identities allows actors to also retain their identification with their constituencies and hence to continue to be effective representatives. In other words, actors can trust their new partners without losing the trust of their constituencies. These findings thus provide guidance to actors representing constituencies with a history of adversarial relations who wish to move beyond conflict to collaboration.

\section{CONCLUSION}

Our primary goal has been to develop a richer theory to explain the linkages between trust and control and to investigate and explain the implications of these connections for the generation of trust. . In exploring the connections between trust and control, we make a number of contributions. First, by synthesizing and building upon the separate literatures, we have developed a framework for understanding how different forms of trust relate to different types of 
control. Second, in so doing, we have been able to identify different control mechanisms available to actors for generating different forms of trust.. Third, within the context of this broader framework, we have shown how identification-based trust can be generated in situations where a history of conflictual relations make both identification and trust problematic. Fourth, we extend discussions of control to include the production of identity, demonstrating how the concept of a discursively constructed identity provides an important link between identificationbased trust and normative control.

Our focus on identity provides insight into the dynamics of discursive activity in the generation of identification-based trust. Specifically, we identify two patterns of discursive reconstruction. The first involves the creation of new categories of identity, or changes to existing ones, in the myths embedded in the domain-level discourse. The second revolves around the assignment of individual actors to particular categories of identity. These individual and domain-level changes are interconnected. Individuals invoke a wider discourse with its concepts, categories and understood relationships and, by constructing individuals as possessing certain identities, can generate predictable behaviour, goodwill and, hence, trust. There are, however, limits to the generation of identification-based trust. While identity is amenable to discursive reconstruction, it can only be 'stretched' so far because discursive activity always occurs within a broader discursive context. So, while CTAC members drew on particular identities, they did not single-handedly create them since the construction of new identities was part of the broader ebbs and flows of multiple discourses, including gay rights and the politics of medical care. Overall, it is clear that the connections between trust, control and identity are critically important and this study provides some first important insights into the complex processes that are involved. 


\section{BIBLIOGRAPHY}

Albert, Terry and Gregory Williams

1997 The economic burden of HIV/AIDS in Canada: Summary of the findings and policy implications. Ottawa, Ontario: Canadian Policy Research Network.

Alvesson, Mats

1994 'Talking in organizations: Managing identity and impressions in an advertising agency'. Organization Studies 15/4: 535 - 563.

Berger, Peter L. and Thomas Luckmann

1967 The social construction of reality: A treatise on the sociology of knowledge. Garden City, NY: Anchor Books.

Clegg, Stewart. R.

1989 Frameworks of Power. London: Sage.

Coleman, James S.

1990 Foundations of social theory. Cambridge, MA: Belknap Press.

Collins, Randall

1981 'On the microfoundations of macrosociology’. American Journal of Sociology 86/5: 9841013.

Coombs, Rod, David Knights and Hugh C. Willmott

1992 'Culture, control and competition: Towards a conceptual framework for the study of information technology in organizations’. Organization Studies 13/1: 51 - 72.

Czarniawska-Joerges, Barbara

1996 'Autobiographical acts and organizational identities' in Understanding Management. S. Linstead, R. Grafton-Small, P. Jeffcut (eds.), London: Sage, 157 - 171.

Das, T. K., and Beng-Sheng Teng

1998 'Between trust and control: Developing confidence in partner cooperation in alliances'. Academy of Management Review 23/ 3: 491-512.

Dasgupta, Partha

1988 'Trust as a commodity’ in Trust: Making and Breaking Cooperative Relations. D. Gambetta (ed.), New York: Basil Blackwell, 49 - 72.

Dodgson, Mark

1993 'Learning, trust and technological collaboration'. Human Relations 46/1: 77-95.

Eisenhardt, Kathleen M.

1989 'Building theories from case study research'. Academy of Management Review 14: 532550.

Epstein, Stephen 
1996 Impure science: AIDS, activism, and the politics of science. Berkeley, CA: University of California Press.

Etzioni, Amitai

1961 A comparative analysis of complex organizations. New York: Free Press of Glencoe.

Faulkner, David

1998 'Are trust and control opposing forces or complementary functions in alliances? - some insights from alliance case studies'. paper presented at 14th EGOS Colloquium, Maastricht, Netherlands.

Fox, Alan.

1974 Beyond contract: Work, power and trust relations. London: Faber and Faber.

Gambetta, Diego

1988 Trust: Making and breaking cooperative relations. New York: Blackwell.

Giglioni, Giovanni B. and Arthur G. Bedeian

1974 'A conspectus of management control theory: 1900 - 1972'. Academy of Management Journal 17: $292-305$

Granovetter, Mark.

1985 'Economic action and social structure: The problem of embeddedness'. American Journal of Sociology 88: 489-515.

Gray, Barbara

1989 Collaborating: Finding common ground for multiparty problems. San Francisco: JosseyBass.

Green, Stephen G. and M. Ann Welsh

1988 'Cybernetics and dependence: Reframing the control concept'. Academy of Management Review 13/2: 287 - 301.

Hardy, Cynthia

1985 'The nature of unobtrusive power'. Journal of Management Studies, 22/4: 384-399.

Hardy, Cynthia and Clegg, Stewart R.

1999 'Some dare call it power' in Studying organization: Theory and method, S.R. Clegg and C. Hardy (eds.), London: Sage, 368-387.

Hardy, Cynthia and Phillips, Nelson

1999 'No joking matter: Discursive struggle in the Canadian refugee system”, Organization Studies, 20/1: 1-24.

Hardy, Cynthia, Nelson Phillips, and Thomas B. Lawrence

1998 'Distinguishing trust and power in interorganizational relations: forms and façades of trust' in Trust within and between organizations, C. Lane and R. Bachmann (eds.), Oxford: Oxford University Press, 64 - 87. 
Holmer-Nadeson, Majia

1996 'Organizational identity and space of action’, Organization Studies, 17/1: 49-81.

Hosmer, Larue Tone

1995 'Trust: the connecting link between organization theory and philosophical ethics'. Academy of Management Review 20/2: 379-403.

Knights, David, Fergus Murray, and Hugh Willmott

1993 'Networking as knowledge work: A study of strategic interorganizational development in the financial services industry'. Journal of Management Studies 30/6: 975-995.

Lane, Cristel and Reinhard Bachmann, editors

1998 Trust within and between organizations: Conceptual issues and empirical applications. Oxford University Press, New York, NY.

Lane, Cristel and Reinhard Bachmann

1996 'The social constitution of trust: Supplier relations in Britain and Germany'. Organization Studies 17/3: 365-396.

Leifer, Richard and Peter K. Mills

1996 'An information processing approach for deciding upon control strategies and reducing control loss in emerging organizations’. Journal of Management 22: 113 - 137.

Lewicki, Roy J. and Barbara Benedict Bunker

1995 'Trust in relationships: A model of development and decline' in Conflict, cooperation and justice: Essays inspired by the work of Morton Deutsch. Barbara Benedict Bunker, Jeffrey Z. Rubin and Associates (eds.), San Francisco, CA: Jossey-Bass Publishers, 133 173.

Lewis, J.David and Andrew Weigert

1985 'Social atomism, holism, and trust'. The Sociological Quarterly 26/4: 455-471.

Litvin, Deborah

1997 'The discourse of diversity: From biology to management'. Organization 4: 187-210.

Lukes, Steven.

1974 Power: A radical view, London; New York: Macmillan.

Luhmann, Niklas

1979 Trust and power. New York: Wiley.

Mayer, Roger C., James J. Davis and F. David Schoorman

1995 'An integrative model of organizational trust'. Academy of Management Review 20/3: 709-734.

McAllister, Daniel J.

1995 'Affect- and cognition-based trust as foundations for interpersonal cooperation in organizations'. Academy Management Journal 38/1: 24-59. 
Mintzberg, Henry

1979 The Structuring of Organizations. Englewood Cliffs, NJ: Prentice Hall.

Nathan, Maria L. and Ian I. Mitroff

1991 'The use of negotiated order theory as a tool for the analysis and development of an interorganizational field’. Journal of Applied Behavioral Science 27: 163-180.

Pfeffer, Jeffrey and Gerald R. Salancik

1978 The External Control of Organizations: A Resource Dependence Perspective. New York: Harper and Row.

Phillips, Nelson and Cynthia Hardy

1997 'Managing multiple identity: discourse, legitimacy and resources in the UK refugee system’. Organization 4(2): 159-185.

Ring, Peter S., and Andrew Van de Ven

1992 'Structuring cooperative relationships between organizations'. Strategic Management Journal 13: 483-498.

Rodrigues, Suzana B.

1996 'Corporate culture and de-institutionalization: Implications for identity in a Brazilian telecommunications company’ in Constituting management: Markets, meanings and identities, S. Clegg and G. Palmer (eds.), 115-137. Berlin: De Gryuter.

Rousseau, Denise M., Sim B. Sitkin, Ronald S. Burt and Colin Camerer

1998 'Not so different after all: A cross-discipline view of trust'. Academy of Management Review 23/3: 393 - 404.

Roy, Charles M.

1995 Living and serving: Persons with HIV in the Canadian AIDS movement. Ottawa: Canadian AIDS Society.

Sabel, Charles. F.

1993 'Studies of trust: Building new forms of cooperation in a volatile economy'. Human Relations 46/9: 1133-1170.

Shapiro, Deborah L., Blair H. Sheppard and Lisa Cheraskin

1992 'Business on a handshake'. Negotiation Journal 8/4: 365 - 377.

Sitkin, Sim B. and Nancy L. Roth

1993 'Explaining the limited effectiveness of legalistic 'remedies' for trust/distrust'. Organization Science 26/4: 367-392.

Sydow, Jorg

1998, 'Understanding the constitution of interorganizational trust' in Trust within and between organizations: Conceptual issues and empirical applications. Cristel Lane and Reinhard Bachmann (eds.), 31-63. New York: Oxford University Press. 
Wachter, Robert $\mathrm{M}$.

1991 The fragile coalition: scientists, activists and AIDS. New York: St-Martin’s Press.

Zucker, Lynne G.

1986, 'Production of trust: institutional sources of economic structure. 1840 - 1920' in Research in Organizational Behaviour, 53-111. Greenwich: JAI. 


\section{Table 1}

\section{Different Forms of Trust and Control}

\section{Calculus-based trust Knowledge-based trust Identification-based trust}

\begin{tabular}{|c|c|c|c|}
\hline Description & $\begin{array}{l}\text { ongoing confidence in } \\
\text { the predictability of the } \\
\text { trustee, grounded in the } \\
\text { calculation of rewards } \\
\text { and punishments }\end{array}$ & $\begin{array}{l}\text { ongoing confidence in } \\
\text { the predictability of the } \\
\text { trustee, grounded in } \\
\text { knowledge of the } \\
\text { trustee }\end{array}$ & $\begin{array}{l}\text { ongoing confidence in the } \\
\text { predictability and } \\
\text { goodwill of the trustee, } \\
\text { grounded in trustee-trustor } \\
\text { identification }\end{array}$ \\
\hline $\begin{array}{l}\text { Type of } \\
\text { control }\end{array}$ & coercive/remunerative & unknown to trustor & normative \\
\hline $\begin{array}{l}\text { Capabilities } \\
\text { required to } \\
\text { generate trust } \\
\text { \& control }\end{array}$ & $\begin{array}{l}\text { ability to reward, punish } \\
\text { and/or discipline the } \\
\text { trustee }\end{array}$ & $\begin{array}{l}\text { ability to observe and } \\
\text { learn about the trustee }\end{array}$ & $\begin{array}{l}\text { ability to shape and to } \\
\text { mould the identity of } \\
\text { trustee and trustor }\end{array}$ \\
\hline $\begin{array}{l}\text { Key resources } \\
\text { needed to } \\
\text { generate trust }\end{array}$ & $\begin{array}{l}\text { resources valued by } \\
\text { trustees, various forms } \\
\text { of incentives and } \\
\text { sanctions (e.g. money, } \\
\text { perks, etc.) }\end{array}$ & $\begin{array}{l}\text { informational } \\
\text { resources (e.g. data, } \\
\text { cognitive \& computing } \\
\text { skills, intelligence, } \\
\text { etc.) }\end{array}$ & $\begin{array}{l}\text { discursive resources (e.g. } \\
\text { access to and voice in key } \\
\text { conversations, etc.) }\end{array}$ \\
\hline
\end{tabular}

$\begin{array}{llll}\begin{array}{l}\text { Process of } \\ \text { generating }\end{array} & \begin{array}{l}\text { active manipulation of } \\ \text { the predictability of the } \\ \text { trust }\end{array} & \begin{array}{l}\text { passive appreciation of } \\ \text { the predictability of the by the trustor by } \\ \text { structuring of rewards } \\ \text { trustee by the trustor }\end{array} & \begin{array}{l}\text { active manipulation of the } \\ \text { predictability and } \\ \text { goodwill of the trustee by } \\ \text { the trustor by discursively } \\ \text { constructing identity }\end{array}\end{array}$




\section{NOTES}

${ }^{1}$ We suggest that this is, in fact, an empirical question that cannot be answered in this particular paper. It may also vary according to context. For example, some situations may be characterized by an evolutionary pattern as CBT evolves into KBT and then into IBT over time. In other situations, elements of all three may be present, perhaps with an emphasis on one or another. It is also possible that the direction of the evolutionary process may change. For example, a change in circumstances may undermine IBT or KBT, leading actors to revert to CBT.

${ }^{2}$ Global epidemiology statistics are from a November 1997 press release of the Joint United Nations Programme on AIDS (UNAIDS). Canadian epidemiological data is from Health Canada's web site (www.hc-sc.gc.ca, last visited 199810 14). Canadian cost data is from Albert \& Williams (1997).

${ }^{3}$ Figure is from the Economist 19961012.

${ }^{4}$ Figures are from the Globe and Mail 19980130 \& 19980521.

${ }^{5}$ Over 40 such substances were listed in the media guide distributed at the 1996 International Conference on AIDS in Vancouver. 


\section{University Library}

\section{- M M N E R VA A gateway to Melbourne's research publications}

Minerva Access is the Institutional Repository of The University of Melbourne

Author/s:

Maguire, S;Phillips, N;Hardy, C

Title:

When 'silence = death', keep talking: Trust, control and the discursive construction of identity in the Canadian HIV/AIDS treatment domain

Date:

2001-01-01

Citation:

Maguire, S., Phillips, N. \& Hardy, C. (2001). When 'silence = death', keep talking:

Trust, control and the discursive construction of identity in the Canadian HIV/

AIDS treatment domain. ORGANIZATION STUDIES, 22 (2), pp.285-310. https:// doi.org/10.1177/0170840601222005.

Persistent Link:

http://hdl.handle.net/11343/116083 